\title{
Developmental processes in peer relations and psychopathology
}

\author{
DANTE CICCHETTI ${ }^{\circ}$ AND WILLIAM M. BUKOWSKI ${ }^{b}$ \\ 'Mt. Hope Family Center, Department of Psychology, University of Rochester; and \\ ${ }^{\circ}$ Concordia University, Department of Psychology
}

The repeated observation that measures of children's experiences with their agemates and measures of concurrent or subsequent behavioral and/or affective maladjustment are interrelated has been a central motivator for the extensive attention researchers have directed toward the peer system during the past two decades. This literature regarding peer relations and developmental outcome and psychopathology is well known, having been reviewed and analyzed in two excellent chapters written by Jeffrey Parker and his colleagues (Parker \& Asher, 1987; Parker, Rubin, Price, \& DeRosier, 1995). This prior research stands as the point of departure for the studies that comprise this Special Issue. The goal of the studies included in this Issue was to take the research literature on peer relations and maladjustment to a new level of conceptual and empirical inquiry. In this regard, these studies represent the forefront of current thinking and research on the

This work was supported by grants from the William T. Grant Foundation, the National Center on Child Abuse and Neglect, the National Institute of Mental Health, the Social Sciences and Humanities Research Council of Canada, the Spencer Foundation, and the Spunk Fund, Inc.

Address correspondence and reprint requests to: cither Dante Cicchetti, Mlt. Hope Family Center, 187 Edinburgh Street, Rochester, NY 14608 or William M. Bukowski, Concordia University, Department of Psychology, 7141 rue Sherbrooke Ouest, Montrèal, Québee HAB IR6, Canada. links between the peer system and the children's current and subsequent level of adjustment.

As a group, the papers are organized around the idea that the study of normal development and the study of risk and psychopathology can be mutually enriching (Cicchetti \& Cohen, 1995). This perspective emphasizes the position that the links between the study of normal developmental processes and the study of risk and maladaptation are bidirectional (Cicchetti, 1984, 1993; Sroufe, 1990). Indeed, the studies in this issue show that the origins of risk and resilience can be understood via a consideration of biological, psychological, and social phenomena that vary across a broadly defined normal range (Rutter \& Garmezy, 1983). Specifically, in the current investigations, measures of peer relations based on theory and research regarding "normal" processes within the peer domain are shown to be powerful antecedents, consequents, or modifiers of phenomena known to be indicators of maladjustment and psychopathology. On the other hand, these studies point to the relevance of "risk" research for the understanding of normal developmental processes. By identifying the processes and constructs that underlie maladjustment, these studies direct our attention to the salience of particular developmental processes from within the normal range. This concern with the bidirectional association 
between research on normality and research on risk and pathology has been the hallmark of studies conducted within a developmental psychopathology framework (Cicchetti, 1984; Sroufe \& Rutter, 1984). The studies in this Special Issue continue and extend this research tradition.

Three particular factors distinguish these investigations from earlier research on peer relations and maladjustment. First, each study brings to bear an explicit theoretical perspective that guides the research linking developmental processes, peer relations, and maladjustment/psychopathology. Rather than relying solely on the elusive concept that peer relations are essential for wellbeing, the authors of these papers provide clear theoretical arguments to explain the nature of this association. Second, the contributors to this Issue demonstrate that the understanding of the constructs represented by particular measures of experience with peers has become increasingly sophisticated. Twenty years ago, persons interested in whether peer relations were linked to behavioral or emotional problems were content to choose any measure of peer relations, without regard for what it might tell us about children's actual experiences within the peer domain, and then determine if it were correlated with an outcome measure. Clearly the times have changed (see Rubin, Bukowski, \& Parker, in press). In the papers included in this Issue, investigators carefully adopted specific measures to index particular theoretical constructs. In this way, these studies illustrate how distinct dimensions of peer experience are differentially linked to adjustment and development. This emphasis on specificity is essential if we want to know how particular aspects of peer experience contribute, either individually or as a group, to the development of maladjustment and maladaptation. Third, in this Special Issue, longitudinal approaches are prominent across the studies. By using longitudinal data these papers move beyond simple demonstrations of correlations between peer relations and adjustment, or simple linear predictions from one to the other. Instead, these studies focus on development as a time-related phenomenon. The importance of utilizing a longitudinal perspective is shown by investigations that reveal different patterns of results for concurrent associations and associations drawn across time. Moreover, these studies are critical for understanding how disorders emerge and how they are maintained.

Despite their similarity along these dimensions, the papers in this Special Issue are also remarkably varied. This diversity is manifested in: (a) the age range of the children studied (i.e., preschool through adolescence); (b) the varied socioeconomic and demographic characteristics of the participants; (c) the observational settings used (e.g., homes, schools, summer camps, laboratories); (d) the measures examined (e.g., popularity, social behavior, friendship); (e) the sources of information (e.g., peer ratings, self ratings, teacher evaluations, experimental procedures, clinical assessments, and behavioral observations); (f the outcomes evaluated (e.g., peer relations, depressive symptomatology, delinquency, substance abuse, externalizing problems); and $(\mathrm{g})$ the conceptualization of the direction of the link between peer measures and maladjustment or disorder (i.e., in some articles peer measures are shown to precede outcome, in other studies disorder is shown to be antecedent to measures of peer relations and psychopathology). Also, a range of developmental pathways is considered. Some pathways eventuate in the same problems or outcomes for different populations or subgroups; other pathways show how some children from the same "risk" groups or with the same disorder have very different developmental trajectories, with some children showing little evidence of psychopathology or even presenting high levels of competence.

This Special Issue illustrates the energy that has been devoted to promoting the theoretical and methodological sophistication evident in the study of peer relations and adjustment. It is clear from these papers that much of the evolution of this literature emanates from a "rapprochement" between the study of peer relations within the nor- 
mal range and the field of developmental psychopathology. The increasing conceptual and empirical strength that derives from this combination will be a major force in subsequent research on peer relations and research on maladaptation and risk. The current studies underscore the continuance

\section{References}

Cicchetti, D. (1984). The emergence of developmental psychopathology. Child Development, 55, 1-7.

Cicchetti, D. (1993). Developmental psychopathology: Reactions, reflections, projections. Developmental Review, 13, 471-502.

Cicchetti, D., \& Cohen, D. (1995). Perspectives on developmental psychopathology. In D. Cicchetti \& D. Cohen (Eds.), Developmental psychopathology. Vol. l: Theory and method (pp. 3-20). New York: Wiley.

Cowen, E. L., Pedersen, A., Babigian, H., Izzo, L. D., \& Trost, M. A. (1973). Long-term follow-up of early detected vulnerable children. Journal of Consulting and Clinical Psychology, 4I, 438-446.

Parker, J. G., \& Asher, S. R. (1987). Peer relations and later personal adjustment: Are low-accepted children at risk? Psychological Bulletin, 102, 357-389.

Parker, J. G., Rubin, K. H., Price, J., \& DeRosier, M. E. (1995). Peer relationships, child development, and adjustment: $A$ developmental psychopathology perspective. In D. Cicchetti \& D. Cohen (Eds.), Developmental psychopathology, Vol. 2: Risk, dis- of the enthusiasm that was generated from the original observations of a link between peer relations and adjustment (e.g., Cowen, Pedersen, Babigian, Izzo, \& Trost, 1973; Rutter, 1989). This Special Issue points to the current vitality of this research domain and predicts a lively and productive future.

order, and adaptation (pp. 96-161). New York: Wiley.

Rubin, K. H., Bukowski, W. M., \& Parker, J. G. (in press). The peer system: Interactions, relationships, and group experiences. In W. Damon (Ser. Ed.) and N. Eisenberg (Vol. Ed.), The handbook of child psychology (5th ed.). New York: Wiley.

Rutter, M. (1989). Isle of Wight revisited: Twenty-five years of child psychiatric epidemiology. American Academy of Child and Adolescent Psychiatry, 28, 633-653.

Rutter, M., \& Garmezy, N. (1983). Developmental psychopathology. In E. M. Hetherington (Ed.). Socialization, personality and social development (pp. 775-911). New York: Wiley.

Sroufe, L. A. (1990). Considering normal and abnormal together: The essence of developmental psychopathology. Development and Psychopathology, 2, 335-347.

Sroufe, L. A., \& Rutter, M. (1984). The domain of developmental psychopathology. Child Development, 55, 17-29. 